\title{
Lingual Frenectomy to Improve Stability of Mandibular Denture: Case Report
}

\author{
Nihel Charfi ${ }^{1 *}$, Dorra Chaabouni ${ }^{2}$, Rim Mabrouk $^{3}$, Sameh Aguir ${ }^{4}$, Rim Bibi $^{5}$, Nadia Frih $^{6}$ \\ ${ }^{1}$ Resident in Removable Partial Prosthodontics, Department of Dental Medicine, Hospital of Charles Nicolle Tunis \\ ${ }^{2}$ Specialist in Oral and maxillofacial radiology, Former Resident in Department of Radiology, University Dental Clinic, 5000 \\ Monastir, Tunisia. \\ ${ }^{3}$ Associate Professor in Endodontics and Restorative Dentistry, Faculty of Dental Medicine of Monastir Department of Dental \\ Medicine, Hospital of Charles Nicolle Tunis Tunisia \\ ${ }^{4}$ Resident in Removable Partial Prosthodontics, Department of Dental Medicine, Hospital of Charles Nicolle Tunis Tunisia \\ ${ }^{5}$ Professor in Removable Partial Prosthodontics, Faculty of Dental Medicine of Monastir, Department of Dental Medicine, Hospital of \\ Charles Nicolle Tunis Tunisia \\ ${ }^{6}$ Professor in Forensic Dentistry and Head of Service, Faculty of Dental Medicine of Monastir, Department of Dental Medicine, \\ Hospital of Charles Nicolle Tunis
}

$\begin{array}{cl}\text { Article History } & \begin{array}{l}\text { Abstract: Tongue-tie is a congenital anomaly characterized by a short frenulum that } \\ \text { can hinder lingual mobility. The lingual frenulum is an anatomical structure consisting } \\ \text { Received: } 17.11 .2020\end{array} \\ \text { essentially of a very dense network of connective fibers which attaches the tongue to } \\ \text { Published: } 09.12 .2020 & \begin{array}{l}\text { the oral floor, should be permitted adequate space at denture border. Otherwise, it will } \\ \text { cause the dislodgement of the denture. The treatment options included frenotomy and } \\ \text { frenectomy. Frenectomy is complete removal of the frenum, while frenotomy is } \\ \text { incision of the frenum. This case reports a 51 year-old, edentulous male patient with } \\ \text { brief lingual frenulum who complained of difficulty in speech, feeding and the } \\ \text { instability of his complete mandibular denture which he underwent conventional }\end{array} \\ \text { Journal homepage: } & \begin{array}{l}\text { lingual frenectomy procedure followed by speech therapy sessions. } \\ \text { Keywords: Tongue tie, ankyloglossia, edentulous patient, lingual frenectomy. }\end{array}\end{array}$

Copyright ( 92020 The Author(s): This is an open-access article distributed under the terms of the Creative Commons Attribution 4.0 International License (CC BY-NC 4.0) which permits unrestricted use, distribution, and reproduction in any medium for non-commercial use provided the original author and source are credited.

\section{INTRODUCTION}

The lingual frenum usually consists of mucosa, dense fibrous connective tissue, and occasionally, superior fibers of the genioglossus muscle that connects the ventral surface of the tongue and the mucosa of the oral pavement [1].

The tongue-tie is a medical designation officially retained by the World Health Organization since 2010 [2]. It replaces the term of ankyloglossia although still used. In the database, their diagnosis were coded using International Classification of Diseases (ICD-10 CA) codes Ankyloglossia -Tongue tie (Q381) [3]. It is defined by Wallace in 1963 as a short lingual frenum that prevents the tip of the tongue to be protruded beyond the lower incisor teeth [4].

In literature Incidence of ankyloglossia range from $0.2 \%$ to $10.7 \%$, depending on the examined population and the definition on ankyloglossia and affects more males at almost a 3:1 ratio $[6,7]$.

A large number of Syndromes associated with tongue-tie have been described such as Pierre Robin syndrome, Trisomy 21, cleft palate, Kindler syndrome, Van der Woude, Opitz and Riga-Fede disease, with a strong impact on family history on its prevalence, associated with an unproven suspicion of transmission by the $\mathrm{X}$ chromosome [6]. Although, this congenital malformation may be the result of cocaine use during pregnancy [7].

Most classifications are based on the type of lingual insertion. The most common classification is the one proposed by Coryllos et al. in 2004 and published under the auspice of the American Academy of Pediatrics [8]. Also the ankyloglossia can be classified into 4 classes based on Kotlow's assessment [9-10] who is a pediatric dentist. The tongue attachment is 
classified by the location of the lingual frenulum insertion to the underside of the tongue specifically the length [8-10]. Class III and IV tongue-tie category should be given special consideration because they severely restrict tongue movement [4].

The presence of a short lingual frenum may be responsible for a low mobility of the tongue, breastfeeding problems, difficulties in speech, feeding, development of gingival recession on the lingual side of the lower front teeth, and also interferes with the stability of mandibular prosthesis.

Lingual frenectomy is a preprosthetic surgical procedure which is also used to improve the stability of removable prosthesis and prevent children from the functional consequences.

\section{Case Report}

A 51-year-old male patient with a type 2 diabetes and high blood pressure following steroid therapy for Berger's disease which's a kidney disease that occurs when an immunoglobulin A damages the glomeruli where blood is cleaned by stocking up leading to kidney failure, was referred to the Dental Department of Charles Nicolle Hospital of Tunis. This results in local inflammation that makes the kidney unable to filter waste from the blood. The patient reports stability problems with his complete mandibular denture.

Clinical examination revealed a short and thin lingual frenum (Figure 1 (a), (b)) that interferes with denture stability leading to a decrease in the sublingual area. During the protraction, the tongue was divided longitudinally giving a mechanical bifidity aspect with a deep fissure formation in the midline of the tongue and an impossibility of leaving the oral cavity (Figure 1 (c)). The physiological posture of the tongue was affected (Figure 2). A Limitation of the elevation of the tongue with the impossibility of touching the retro incisor space with the tip of the tongue was noted (Figure 2 (a)). Each time the tongue was moved, the frenal attachment was tensed and the denture was dislodged (Figure 2 (b)). Treatment plan for the patient included surgical correction of Ankyloglossia, a soft tissue conditioning followed by speech therapy for an immediate rehabilitation of the lingual muscle.

\section{Surgical procedure}

Two day before the procedure, antibiotic prophylaxis was given to the patient to prevent the development of either systemic or local infection complications related to autoimmune Berger's disease.

The first step in frenectomy was bilateral infiltration of local anaesthesia; a traction suture was then applied at the tip of the tongue (Figure 3 (a)), to firmly retract the tongue in order to give better visibility. The frenum was held with a hemostat. A horizontal incision was made half-way the frenum (Figure 3 (b)). Then a slight detachment of the mucous membrane was performed to resect the fibrous structures located deeper and which were responsible for the shortness of the frenulum (Figure 3 (c)). After that, a transverse incision was done above and below the area (Figure 3 (d)) which performed a diamond shaped wound (Figure 3 (e)).

The first points were placed at the boundaries of the primary incision using 3-0 silk suture VICRYL®. The other points were placed successively, equidistant between the initial points (Figure 3 (f)).

The patient was recommended to continue the antibiotic therapy for 5 days to prevent infection. Additionally, he was put on analgesics to manage pain. An anti-inflammatory can be prescribed reduce the edema.

\section{Postsurgical procedure}

Immediately after the procedure, a spectacular and immediate result was noted (Figure 4). A soft tissue conditioning was required immediately following the surgical act using a tissue conditioner materiel like functional Impression Tissue Toner kerr $₫$ by lining the intrados of the prosthesis with the delayed setting resin. The emphasis should be on the sublingual border. Simultaneously the patient must perform Thabet movements (Figure5).

Sutures were removed after one week, at which time healing was almost complete. After twenty five days of complete healing (Figure 6), a functional reline impression was taken using polysulfide molded by speech exercises to record the extensions (Figure 7).

The denture borders are formed by functional and physiogical movements using thermoplastic border recording impression (Figure 7(b)), patient's tongue movements record the lingual borders Dynamic impression was recorded with Permlastic ${ }^{\mathrm{TM}}$ impression material kerr $^{\circledR}$ (Figure 7(c)). 

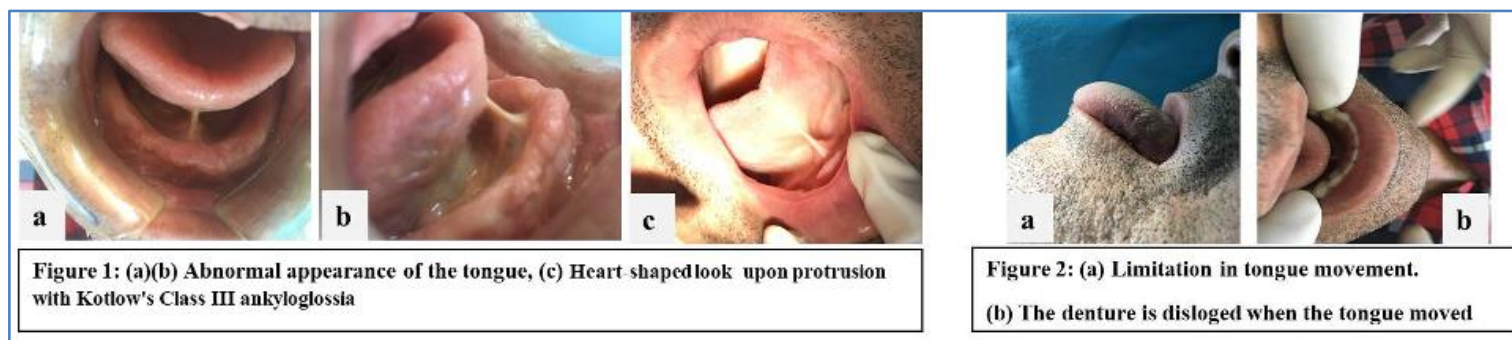

Figure 2: (a) Limitation in tongue movement.

(b) The denture is disloged when the tongue moved

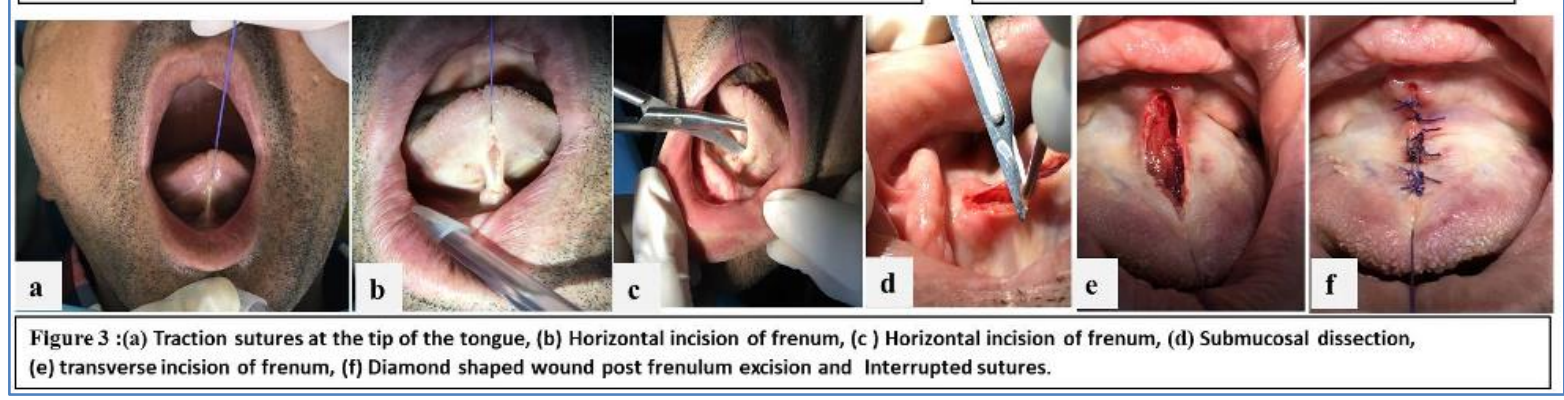

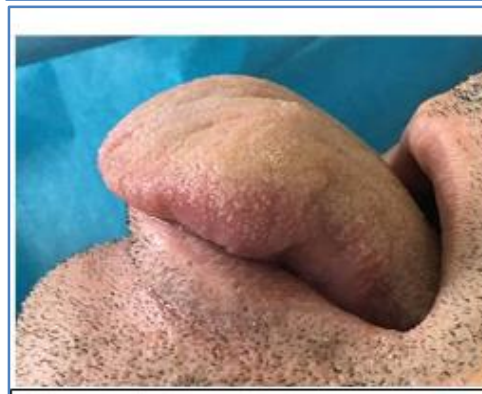

Figure 4: An immediate improvement in protraction after treatment

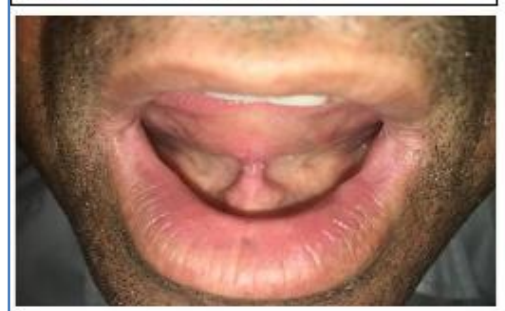

Figure 6: Healing 25 days Post operative
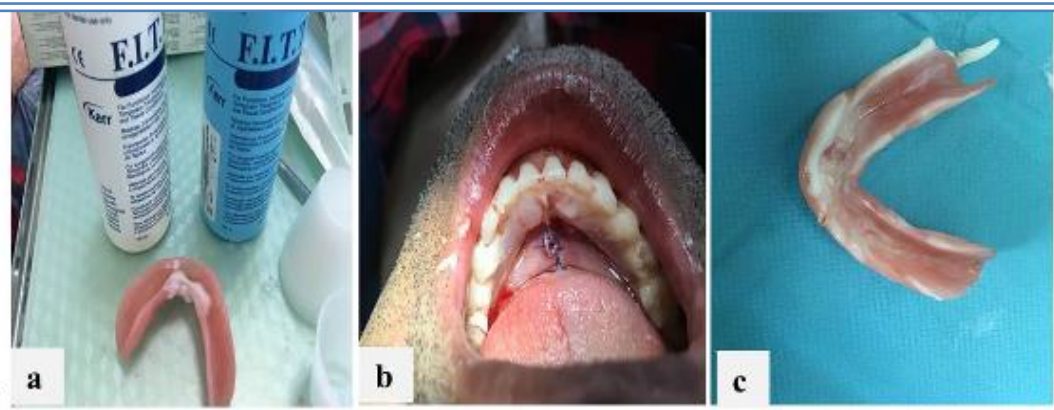

Figure 5 : (a) (b) Tissue conditioning is essential immediately after the surgery followed by speech therapy for an immediate rehabilitation, (c) Note the lack filled by the delay resin
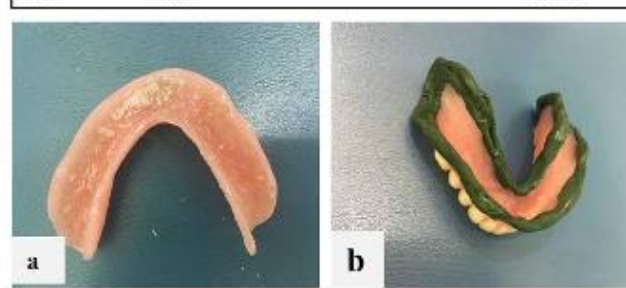

Figure 7: (a) $1 \mathrm{~mm}$ reduction of the edges and lower surface of the prosthesis, (b) Realization of the peripheral seal with thermoplastic paste, (c) Tertiary impression with polysulfide

\section{DISCUSSION}

Tongue beyond being one of the strongest muscular organs of the body, is also associated with important functions like mastication and phonation. Besides these known function, it has a psychologically harmful effect when its movement are restricted [11].

Furthermore, it should be also stated that a short frenum is not always inelastic or fibrotic and, despite the reduced length, it may allow a normal lingual mobility thus not necessitating a reduction intervention. Also, the elasticity of the floor of the mouth may still allow a normal mobility of the tongue thus making the frenectomy unnecessary [5].

Lingual frenectomy procedures are more challenging than labial frenectomy procedures due to the hypermobility of the tongue; and the proximity to the submandibular ducts and the richly vascular floor of the mouth [4]. That's why lingual frenectomy technique requires surgical dexterity. Otherwise, Laser Diode technique is an excellent alternative to traditional surgery. Besides, this rapid and simple therapy is always better accepted than traditional therapy. In fact, it is seen by the patient as a less invasive instrument; the post-operative period is usually asymptomatic and relapse is minimal or absent $[5,12,13]$.

However, it's associated with certain complications which include laser-induced thermal necrosis photo acoustic injury [12].

Yet the tongue is usually considerate as a very disturbing factor in every phase of dental prosthesis.

In partial removable prosthesis, the presence of short lingual frenulum does not have significant consequences on the prosthetic balance, since the retention stability is not only based on the mucosal 
bearing surface, but also on the stability and dentoprosthetic retention.

However, in complete denture, according to Fish [12] the accommodating the functional areas of the tongue insure stability of lower dentures. The sublingual flange extension increases the tissue surface without interfering the functions of mastication, deglutition and phonation. And it utilizes the inherent elastic recoil of the soft tissues in the area to develop positive retention upon the anterior part of the denture base [5]. The active incorporation of tongue activity also stabilizes the denture [12].

Problems of stability of complete removable prosthesis due to lingual brevity can also be solved by piezography technique which record the neutral zone so the teeth will not interfere with normal muscle function, it enhance retention stability and function for the mandibular denture $[14,15]$ as well as the use of implants as supports for additional retention means [15].

\section{Conclusion}

Tongue tie has a psychosocial impact on such patients especially in relation to maintaining social relationships. Fortunately, Treatment of the lingual frenum can be easily corrected at any age, and even better successfully treated in the dental office. Yet, the early diagnosis and management of patients may offer better chances to prevent alterations correlated to the ankyloglossia.

\section{REFERENCES}

1. Mills, N., Pransky, S. M., Geddes, D. T., \& Mirjalili, S. A. (2019). What is a tongue tie? Defining the anatomy of the in-situ lingual frenulum. Clinical Anatomy, 32(6), 749-761.

2. World Health Organization (WHO). (2010).International Statistical Classification of Diseases and Related Health Problems, 10 révision. Genève : WHO.

3. Lisonek, M., Liu, S., Dzakpasu, S., Moore, A. M., \& Joseph, K. S. (2017). Changes in the incidence and surgical treatment of ankyloglossia in
Canada. Paediatrics \& Child Health, 22(7), 382386.

4. Wallace AF.(1963). Tongue tie. Lancet.; 2:377-8.

5. BHAT, Divya et SUCHETHA, A. Lingual frenectomy to treat ankyloglossia--a perioprosthetic venture. Indian Journal of Dental Advancements, 2010, vol. 2, no 3, p. 282-285.

6. Olivi, G., Signore, A., Olivi, M., \& Genovese, M. D. (2012). Lingual frenectomy: functional evaluation and new therapeutical approach. Eur $J$ Paediatr Dent, 13(2), 101-6.

7. SeemaBargale, A. D., Macwan, C., \& Sikligar, S. Ankyloglossia in the Infant and Young Child: A Review.

8. International Affiliation of Tongue Tie Professionals. <https://tonguetieprofessionals.org/> (Accessed August 25, 2020).

9. Dezio, M., Piras, A., Gallottini, L., \& Denotti, G. (2015). Tongue-tie, from embriology to treatment: a literature review. Journal of Pediatric and Neonatal Individualized Medicine (JPNIM), 4(1), e040101.

10. Kotlow, L. (2015). TOTS-tethered oral tissues the assessment and diagnosis of the tongue and upper lip ties in breastfeeding. Journal of Oral Health.

11. Francis DO, Chinnadurai S, Morad A, Epstein RA, Kohanim S, Krishnaswami S, et al. (2015 ).Treatments for ankyloglossia and ankyloglossia with concomitant lip-tie [Internet]. Rockville (MD): Agency for Healthcare Research and Quality (US).

12. Kessler, B. (1955). An analysis of the tongue factor and its functioning areas in dental prosthesis. Journal of Prosthetic Dentistry, 5(5), 629-635.

13. Devishree, S. K. G., \& Shubhashini, P. V. (2012). Frenectomy: a review with the reports of surgical techniques. Journal of clinical and diagnostic research: JCDR, 6(9), 1587.

14. Bhattacharyya, J., Goel, P., Ghosh, S., \& Das, S. (2012). Piezography: An Innovative Technique in Complete Denture Fabrication. J Contemp Dent, 2(3), 109-113.

15. Patel, J., Jablonski, R. Y., \& Morrow, L. A. (2018). Complete dentures: an update on clinical assessment and management: part 1. British Dental Journal, 225(8), 707-714. 